\title{
The Metabolic Plant Feedback Hypothesis: How Plant Secondary Metabolites Nonspecifically Impact Human Health*
}

Author

Affiliation
Jürg Gertsch

Institute of Biochemistry and Molecular Medicine, University of Bern, Bern, Switzerland

\author{
Key words \\ - evolution of diet \\ - glucotoxicity \\ - chlorophyll \\ - paleolithic diet \\ - natural products \\ - diabetes
}

\section{Abstract \\ $\nabla$}

Humans can ingest gram amounts of plant secondary metabolites daily through diet. Many of these phytochemicals are bioactive beyond our current understanding because they act through weak negative biological feedback mechanisms, undetectable in vitro. Homeostatic-type assessments shed light on the evolutionary implications of the human diet from plants, giving rise to the metabolic plant feedback hypothesis. The hypothesis states that ancient diets rich in carbohydrates coincide with bulk dietary phytochemicals that act as nonspecific inhibitors of metabolic and inflammatory processes. Consequently, foodderived phytochemicals are likely to be equally effective as herbal medicines for these indications.

No disease that can be treated by diet should be treated with any other means.

Moses Maimonides [1139-1204]

$\begin{array}{ll}\text { received } & \text { March 23, } 2016 \\ \text { revised } & \text { April 24, 2016 } \\ \text { accepted } & \text { April 29, 2016 }\end{array}$

Bibliography

Dol http://dx.doi.org/

10.1055/s-0042-108340

Published online June 10, 2016

Planta Med 2016; 82: 920-929

(c) Georg Thieme Verlag KG

Stuttgart · New York .

ISSN 0032-0943

Correspondence

Prof. Jürg Gertsch

Institute of Biochemistry and

Molecular Medicine

University of Bern

Bühlstrasse 28

3012 Bern

Switzerland

Phone: + 41316314124

juerg.gertsch@ibmm.unibe.ch

\section{A Personal Prelude on Hunter- Gatherer Nutrition \\ $\nabla$}

Beginning around $11000 \mathrm{BC}$, the transition from the hunter-gatherer lifestyle to agriculture enabled people to settle down next to their permanently cultivated lands instead of migrating to follow seasonal changes in wild food supplies. During my memorable episodes of fieldwork among the Yanomamï Amerindians in the upper Orinoco in Venezuela (1998-2002), I realized how the diet of a seminomadic hunter-gatherer society differs from the diet of an industrialized society. I was able to record the regular use of about 150 edible

\footnotetext{
* Dedicated to Professor Dr. Dr. h.c. mult. Kurt Hostettmann in recognition of his outstanding contribution to natural product research.
}

In addition to the ubiquitous flavonoids, terpenoids, and fatty acids in the diet, the likely impact of chronic chlorophyll ingestion on human health is discussed, and data on its modulation of blood glucose levels are presented. A major deduction of this hypothesis is that starchy diets lacking plant secondary metabolites are associated with multimorbidity (lifestyle diseases) including obesity, type 2 diabetes, and cardiovascular disease. It is proposed that the intake of leafy vegetables, spices, and herbal remedies rich in phytochemicals matches the transition and genetic adaptation to early agriculture, playing a compensatory role in the mismatch of old genes and new diets.

Supporting information available online at http://www.thieme-connect.de/products wild plant taxa in the primary tropical rainforest $[1,2]$ and experienced the sensation of hunger during periods of scarce food. Like any human population, the Yanomamï strive for subsistence involving the search for proteins, carbohydrates, and fats. Yet, it is difficult for them to obtain sufficient carbohydrates and proteins. Headland (1987) pointed out that without a constant source of carbohydrates, the long-term survival in a tropical rainforest is unlikely [3]. Indeed, foraging requires energy, and only a steady source of carbohydrates may guarantee population growth. After the introduction of the plantain (Musa paradisiaca L.; Musaceae) by the Spanish conquistadores in the 16th Century, the Yanomamï, and basically all lowland Amerindian ethnic groups that did not farm cassava (Manihot esculenta Crantz; Euphorbiaceae) or corn (Zea mays L.; Poaceae), started to use this Old World staple crop. This enabled indigenous ethnic groups to migrate into remote forest areas, escaping European slave hunters. Prior to this New World "banana revolution" the Yanomamï were dependent on wild Clathrotropis 
spp. (Leguminosae) seeds, some wild tubers, and Bactris gasipaes HBK, which they semidomesticated in the epicenter of their original habitat (Parima highlands at the border of Venezuela and Brazil) [1]. It is noteworthy that no present-day foraging societies are known which do not engage in some kind of carbohydrate farming and the "contemporary Neolithic hunter gatherers" appear to be more of a textbook phenomenon than a reality. Dietary starch was fundamental for the cognitive development of the carbohydrate craving Homo sapiens [2]. Retrospectively, dietary carbohydrates were essential for the evolution of the human brain, which uses up to $25 \%$ of the body's energy and up to $60 \%$ of blood glucose. Accordingly, salivary amylase (AMY1) genes, which are usually present in several copies in humans, correlate positively with salivary amylase protein levels (individuals from populations with high-starch diets have, on average, more AMY1 copies than those with traditionally low-starch diets) [4], but AMY1 exists only in two copies in other primates. High copy numbers of AMY1 increases the amount of salivary amylase produced and so increases the ability to digest starch [5]. Not surprisingly, sugar intake is linked to the central reward system through a complex interplay of dopaminergic, endorphine, and endocannabinoid signaling, thus reinforcing the motivation to eat sugars. Moreover, excessive sugar intake was associated with a reward deficiency syndrome [6]. Due to constant environmental and political changes (heavy rainfall, droughts, warfare, or epidemics), hunter-gatherers face periods of very low carbohydrate intake, somewhat resembling the Stone Age (Paleolithic) diet described by Walter L. Voegtlin [7], who was among the first to emphasize the genetic adaptation to diet. The foods available to evolving humans must have varied widely according to the paleontological period, geographical location, and seasonal conditions. The most dramatic dietary change came with agriculture. Farmers had advantages over hunter-gatherers, and conquered lands and developed more complex economies. In addition to the gradually more excessive carbohydrate intake in agricultural societies, one can observe a persistent consumption of green leafy vegetables and the use of spices. Spices may have fostered the transition of food to using herbal remedies [8,9]. As pointed out by Diamond [10], plant and animal domestication are the most important developments in the past 13000 years of human history. A regular intake of carbohydrates, without doubt, provides competitive advantages to humans, but as in any biological system there is a tradeoff related to metabolic adaptation. In the last decades, the excessive use of refined carbohydrates (sugars) in many foodstuffs clearly represents a new era of glucotoxicity in the human diet. Although natural selection has provided us with nutritional adaptability, modern human beings are confronted with dietrelated health problems [11-13] that go beyond the generally increased life span (age). The most striking ad hoc observation relates to hunter-gatherer societies, who upon changing their nutrition through acculturation adopt their diet to processed carbohydrates (including soft drinks and refined sugars), and then start to develop multimorbidity exemplified by obesity, the metabolic syndrome, prediabetes, type 2 diabetes mellitus (T2DM), cardiovascular problems, neuroinflammation, and arthritis. This phenomenon also has an epigenetic dimension because the diet alteration of the parents appears to affect the health of the children $[14,15]$. While one cannot claim that hunter-gatherer societies used to live healthier or longer (actually, they live significantly shorter and much more frequently die from infectious diseases), we can say that in their traditional lifestyle they conserved a more ancient diet, and generally ingested more plant secondary metabolites and less carbohydrates. Upon becoming sedentary, or by changing their diet, even younger individuals from indigenous ethnic groups rapidly develop chronic metabolic and inflammatory diseases [16-19]. Virtually all indigenous populations who recently shifted to high carbohydrate diets suffer from the interrelated phenomenon of glucotoxicity and lipotoxicity, pointing towards the fundamental link between diet and health. Often, acculturation also leads to psychiatric disorders, including lack of motivation and depression, potentially linking the role of sugar intake in the reward deficiency syndrome. It has been argued that traditional societies lack lifestyle diseases and upon acculturation suffer from a "New World Syndrome" [20] as, e.g., pointed out with the Australian aborigines [21]. A recent study suggests that the intake of phytochemicals from a hunter-gatherer diet may help maintain visual acuity and prevent degenerative eye conditions [22]. In summary, the effects of changing ancient diet patterns on pathophysiological processes, probably also mediated by reduced physical activity, are dramatic.

Another observation that relates to my own fieldwork in Venezuela, Sarawak, Mexico, and Bolivia, and to the work of many ethnobotanists is the unequal distribution of knowledge and use of medicinal plants among agriculturalist ethnic groups and hunter-gatherers. In studying the actual use (not just the reports) of medicinal plants worldwide, it becomes evident that foraging societies with limited or primitive staple crop farming use significantly less orally ingested medicinal plants than do professional carbohydrate farming societies (e.g., in Latin America). This is somewhat contrary to some idealized ethnobotanist reports on the vast knowledge systems related to herbal remedies in hunter-gatherer societies. Carbohydrate farming prior to the globalization of starchy plants in the 16th Century was already widespread in Africa (yams, cereals, plantains), Europe (cereals, peas, lentils), Asia (yams, rice, beech, sago), and the Americas (corn, squash, potatoes, cassava, beans). Only small foraging nomadic ethnic groups relied on wild tubers, seeds, and fruits for subsistence. Based on ethnographical data, I conclude that hunter-gatherer groups have the least advanced medicinal plant knowledge systems [23-25] and primarily rely on spiritual healing (shamanism) and the extensive use of psychoactive or magic plants. Among the Yanomamï in Venezuela, the actual use of ingested medicinal plants (i.e., infusions, decocts, etc.), reflecting a more Western concept of herbal medicine, was largely absent, as noted already by Zerries and Schuster [26]. This is in contrast to what was reported from the Yanomamï in Brazil [27]. Allegedly, knowledge on medicinal plants quickly spreads from one ethnic group to another by horizontal knowledge transfer, and its origin is difficult to assess [28]. The major pharmacopoeias used today, including the ramifications of traditional Chinese medicine, the numerous Mediterranean interpretations of De Materia Medica from Dioscurides, or the Mesoamerican pan-Mayan and Andean herbal medicines, originate from ancient cultural backgrounds that have diets rich in carbohydrates due to agriculture. It is tempting to postulate that the lack of bulk phytochemicals once ingested in pre-agriculturist times gradually had to be compensated by spices and herbal remedies in the carbohydrate farming societies to diminish the mismatch of ancient genes and new diets. A special case represents the pastoralist societies in the sub-Saharan regions who started to farm livestock prior to agriculture [29] ( Fig. 1). A pastoralist diet resembles a hunter-gatherer diet, which consists of $65 \%$ animal food (total energy) and the remaining $35 \%$ coming from wild plant sources [30], including starchy plants. Typical carbohydrate farming diets consist of 


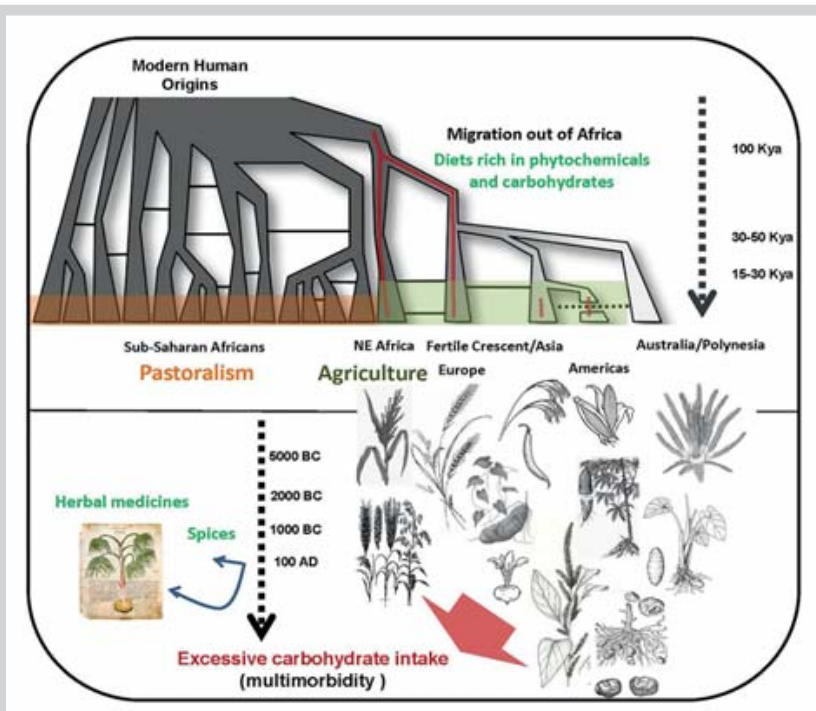

Fig. 1 The evolution of the modern diet started with agriculture between 8500 and 2500 BC in the Fertile Crescent, Northeastern Africa, Asia, and the Americas. Isolated from out-of-Africa migration, the Sub-Saharan people developed animal domestication prior to agriculture. With the rise of carbohydrate farming and subsequent gradual loss of the overall intake of phytochemicals (culminating in the Western diet), early lifestyle diseases originated based on a metabolic and epigenetic collision of our ancient genome with the new conditions of life. This mismatch may have triggered the development of traditional herbal pharmacopoeias within the last 2-4 thousand years. The lack of foodstuffs rich in phytochemicals was compensated by orally ingested medicinal plants and the trade of spices among agriculturalist societies. Kya: thousand years ago. (Color figure available online only.)

about 45-65\% carbohydrates (total energy). The transmission of carbohydrate farming and the use of medicinal plants may coincide and likely presents an important association between food and medicine [31-34]. Elaborating on the metabolic plant feedback hypothesis, if there is a high intake of phytochemicals, there is no need to ingest medicinal plants. By stating the hypothesis that common phytochemicals have nonspecific effects on pathophysiological processes in humans one also raises the question about the underlying mechanisms.

\section{The Neglected Power of Nonspecific Molecular Interactions \\ $\nabla$}

Decades of natural product research and the quest for novel druglike molecules from nature have shown that numerous abundant secondary metabolites in plants show the features of pan-assay interference compounds (PAINS) in vitro [35-37]. Many of these include dietary polyphenolic molecules (flavonoids, diarylheptanoids), phytosterols, and monoterpenes. Nonspecificity or molecular promiscuity is probable when binding interactions are broad and lead to the inactivation of a gene or protein function. When a small molecule binds to a protein with a given thermodynamic signature (enthalpy and entropy), the likelihood of inhibition of this protein is considerably higher than the likelihood of activation. Therefore, most binding events lead to the inhibition or blockage of a protein function. On the other hand, if a phytochemical is critically involved in the activation of a particular biochemical function, it is vitamin-like or involved in activating bio- chemical sensors. For example, many lipophilic molecules are sensed as xenobiotics by nuclear receptor proteins [e.g., peroxisome proliferator-activated receptors (PPARs) or transcriptional activators like androstan receptors] and nonspecifically activate these transcription factors. Consequently, nuclear receptors rather nonspecifically recognize lipophilic phytochemicals [38, 39] as a loop function in the metabolic plant feedback. Nonspecific protein modifications and the induction of a "heat shock response" were shown to contribute to the effects of some phytochemicals $[40,41]$. Nevertheless, the bulk of phytochemicals are protein function inhibitors, at least in vitro. If sufficient amounts of phytochemicals (or metabolites thereof) reach enzymes and receptors, they will negatively modulate them. This has been predominantly observed with polyphenols, which are still widely described as health-promoting antixodiants. However, as pointed out by Virgili and Marino, the "antioxidant hypothesis" of polyphenols may be an intellectual shortcut and not that important in real pathophysiology, contrary to the widespread radical scavenger paradigm [42]. Numerous studies have shown that phytochemicals can inhibit gene expression through protein inhibition or epigenetic mechanisms of genes involved in inflammatory processes [43-45]. Nonspecific epigenetic effects on inflammatory and metabolic processes are likely to play a role, and direct or indirect anti-inflammatory phytochemicals are much more frequent than immune-stimulating phytochemicals [46]. Although these nonspecific natural products are generally poorly bioavailable, their wide abundance in vegetable products makes them interesting candidates for mediators of a negative metabolic feedback.

\section{Plant Secondary Metabolites in Food - Collateral Damage or Metabolic Adaptation?}

$\nabla$

The biggest challenge to study the potential physiological role of non-vitamin plant secondary metabolites in a diet is their differential absorption, distribution, and metabolism. Some plants are specialized to be eaten by mammals, and their gene pools have greatly benefited from this interaction, e.g., through seed dispersal [47]. If not manipulated by horticultural selection, starchy plants tend to produce toxins to deter herbivores and economize on the primary metabolism. Humans are the only mammalian species that strategically cultivate and farm plants. For species of the Poaceae family, initial grain size increases may have evolved during the first centuries of cultivation, within perhaps 5001000 years [48]. The non-shattering infructescences from Leguminosae were much slower, becoming fixed about 1000-2000 years later [48]. The cultivation of starchy plants makes sense, but why were green leafy vegetables like salads successful? In light of the metabolic plant feedback hypothesis, vegetables have modulatory physiological functions counteracting the effect of excessive blood glucose and metabolic inflammation because they contain large amounts of phytochemicals and fibers. As comprehensively summarized by the Linus Pauling Institute Micronutrient Information Centre at Oregon State University [49] and The USDA Database for the Flavonoid Content of Selected Foods (http://www.ars.usda.gov/News/docs.htm?docid=6231), plant secondary metabolites are abundant in vegetables and fruits. In mammals, phytochemicals are absorbed and processed as xenobiotics with none, likely, or yet unknown health benefits, or as vitamins. Maybe the most frequent mistake in natural product research is the assumption that phytochemicals gener- 
ally reach high tissue concentrations upon oral ingestion, leading to rather noncritical correlations of mechanistic in vitro data with pharmacological effects [50-52]. Irrespective of our perception about phytochemicals either as ingredients of herbal remedies or potential drugs, they are present in vegetable foods in substantial amounts [53-55]. Being foreign (xenobiotics), due to their small size, phytochemicals are not recognized by the adaptive immune system, but passively (or by hitchhiking transporters) penetrate our organs. After one or several passages through the liver, they are metabolized and excreted. The long recognized principle that nutritive and toxic effects of an ingested material depend not only on its nature, but also very much on its quantity, has been reviewed by Gerber et al. [56]. In diets, the tendency for organisms to become increasingly adapted to those environments to which they are most commonly exposed is fundamental and relates to the metabolic cost of adaptation [57]. It would be naïve to assume that our genetic adaptation to the environment occurred independent of phytochemicals. The amounts of foreign metabolites that need to be detoxified by our liver as a consequence of fruit and vegetable ingestion should be seen as an adaptive process involving potential costs and fitness benefits. The striking evolution of vitamins (vide infra) is probably the best example for genetic adaptation to phytochemicals. For about $99.8 \%$ of human history there was no agriculture, until it emerged independently in up to nine areas on four continents in the short span of 6000 years between 8500 and 2500 BC [10]. The dramatic metabolic changes of switching from a high phytochemical diet (e.g., hunter-gatherer diet) to a low phytochemical diet (e.g., fast food) are important for these considerations. Clearly, the diversity of the total bioavailable dietary plant natural products and metabolites thereof remains unknown and varies with diet, culture, and lifestyle [58]. While numerous and, in part, conflicting health claims about food-derived vegetable antioxidants and fatty acids have been made [59-68], there is no doubt that the use of dietary plants coevolved with the mammalian diet within a food-medicine continuum [30-33]. The intriguing question is why humans eat what they eat, and how this may affect health and fitness through selection and epigenetic mechanisms $[14,15,69-71]$. For most of the history of human subsistence the organization of stable food sources was a primary focus. For hundred thousands of years the consumption of phytochemicals went hand in hand with the intake of energy. Only in recent decades did the excess of food (sugar, fat, and proteins) in big parts of the world become an evident problem [72-74]. For instance, in Mexico, a special tax on sugar-containing drinks was introduced because Mexico faces an obesity and rising diabetes crisis [75]. Great Britain has recently been discussing a similar tax. Too much carbohydrates, fatty acids, and proteins, and the lack of fruits and vegetables cause pathophysiological alterations that lead to the onset of multimorbidity [76]. Interestingly, new traditional and complementary ethnopharmacological interventions to treat obesity by using medicinal plants, T2DM, and cardiovascular issues have been reported [77-87]. It is quite unlikely that this knowledge is ancient (pre-agriculturist), because these diseases are associated with an agriculturist lifestyle or even more modern lifestyles. The use of plants (other than in diet) may thus represent a dynamic compensation for a general lack of phytochemicals. Consequently, plants that are not part of a diet are selected and ingested to provide the metabolic feedback that is widely lacking in parts of the Western diet. Paradoxically, the more recent ingestion of new medicinal plants, which are also booming in Western societies, is increasing the risk for novel toxicities [88] not seen with nutritional phytochemicals.

\section{Homeostatic-Type Model Assessments - What Do They Tell Us?}

Homeostatic-type model assessments are analytical measurements of important metabolic parameters reflecting the function and fitness of particular organs. Such model assessments can reveal the effects of plant-derived secondary metabolites on specific tissue functions in a genetic population. It cannot be ignored that a very high number of plant extracts in controlled laboratory studies seem to exert beneficial effects on inflammatory and metabolic diseases by largely unknown mechanisms [89-96]. Strikingly, it appears that almost any plant extract is somehow effective. In the last decade, numerous reports were published on different plants (both medicinal and dietary) being effective in animal disease models related to metabolic diseases, suggesting general nonspecific inhibitory effects. I conclude that these inhibitory effects on metabolic and inflammatory gene expression and protein function are real and mediated via nonspecific network effects (vide supra). Possibly, such weak effects may not even be detected in vitro due to restricted insights into the bioavailability, despite the promise of the latest omics methodologies. Indeed, researchers still struggle to measure or simulate the plasma and tissue concentrations of most of the dietary phytochemicals. Fascinated by molecular mechanisms, it is hard to think of dietary phytochemicals as mostly nonspecific negative modulators. The idea of nonspecific effects that have been selected during evolution is uncomfortable. With the elucidation of vitamins, exemplified by the milestone discovery of the molecular mechanism of scurvy (Barlow's disease) and the role of ascorbic acid (vitamin C) from plants as an essential cofactor of prolyl and lysyl hydroxylases (key enzymes in collagen biosynthesis), the general awareness that plants are healthy beyond their nutritional value turned universal. The Scottish surgeon James Lind first conclusively reported that scurvy could be treated with citrus fruits in experiments he described in his 1753 book A Treatise of the Scurvy [97]. In 1912, the Polish American biochemist Casimir Funk (1884-1964), who obtained his PhD from the University of Bern in 1904, coined the term "vitamine". Funk's legacy was the assertion that vitamins are amines and inherent in plant food, and have a single action that is relevant to a specific disease [98]. While it is true that most vitamins are dietderived, vitamins are effective for multiple diseases and are a chemically diverse class of secondary metabolites. The major period of discovery in vitamin research began in the early nineteenth century and ended in the mid-twentieth century [99, $100]$ with the rise of molecular biology. Nonetheless, new potentially important dietary factors among phytochemicals are being uncovered as illustrated by the most abundant dietary plant sesquiterpene, beta-caryophyllene, which exerts broad anti-inflammatory effects in numerous animal models via a particular receptor system [101-103]. Rather than trying to understand how each single phytochemical potentially interacts with a protein target, a homeostatic-type assessment takes human physiology as a quasi-black box, assuming that nature operates with mixtures, numerous weak binding interactions, and synergies [51, 104-106]. All the known pathophysiological parameters (glucose, insulin, serum creatinine, transaminases, albumin, blood urea nitrogen, hematocrit, ferritin, cholesterols, C-reactive pro- 
tein, triglycerides, cortisol, etc.) correlating with function can be measured as a readout from a genetically variable population (outbred humans rather than inbred mice). The input could be the differential diet, or supplementation by specific groups of phytochemicals. This type of assessment is able to shed light on the physiological effects diet has in humans, and is likely to be more significant than animal models. For example, the original homeostatic model assessment (HOMA) is a relatively exact method used to quantify insulin resistance and beta-cell function. It was first described under the name HOMA by Matthews et al. in 1985 by measuring blood glucose and insulin [107]. Instead of attempting to elucidate mechanisms of action of single phytochemicals in a diet, we should also study the broad metabolic effects of mixtures of phytochemicals in the diet. Like HOMA estimates steady state beta cell function and insulin sensitivity, the effects of dietary phytochemicals could be easily assessed by measuring markers predictive of organ fitness (e.g., CNS, heart, liver, kidney, pancreas, adrenals).

\section{Chlorophyllin Exerts a Negative Feedback on Blood Glucose Levels \\ $\nabla$}

The evolution of the ancestral hominid diet is closely linked to chlorophyll intake. It is counterintuitive that bulk chlorophyll ingestion (which can be chronic through diet) should have no impact on mammalian physiology. There is increasing evidence that chlorophylls or their metabolites are bioactive in men (vide infra). The observation that different types of carbohydrate sources lead to differential glucose levels and corresponding insulin secretion led to the concept of the glycemic index of food [108]. A recent study concludes that personalized diets may successfully modify elevated postprandial blood glucose and its metabolic consequences [109]. People eating identical meals present high variability in post-meal blood glucose response, which may be due to genetic background, dietary habits, physical activity, and gut microbiota [109]. Elevated postprandial blood glucose levels are considered a global epidemic, as they are a major risk factor for prediabetes and T2DM.

In order to assess the potentially negative impact of chlorophylltype molecules on blood glucose, a simple homeostatic-type assessment was carried out (see Supporting Information). Young male volunteers (21-25 years old) were subject to a classical glucose tolerance test. After overnight fasting, $75 \mathrm{~g}$ of glucose in $3 \mathrm{dL}$ of water alone or in the presence of $1 \mathrm{~g}$ of chlorophyllin (E141) was ingested, and the blood glucose levels were measured over $120 \mathrm{~min}$ from capillary blood ( Fig. 2) and compared to fasting (time zero). Interestingly, statistically significant differences were found with the peak blood glucose levels at 30 and $60 \mathrm{~min}$ between the control and chlorophyllin, indicating a net decrease of blood glucose by about $1 \mathrm{mM}$ ( Fig. 2). This may suggest that ordinary spices and green leafy vegetables might acutely impact the glycemic index of glucose and, most likely, other foodstuffs due to the effects of chlorophyll (if identical to food chlorophyllin). While it is not clear how this works, chlorophyllin may interfere with gut glucose transporters or incretin signaling, e.g., acting as a glucagon-like peptide 1 (GLP-1) secretagogue. It is already known that chloroplast thylakoids reduce glucose uptake and suppress blood glucose levels $[110,111]$. Moreover, daily supplementation with green plant membranes for three months significantly reduced weight in overweight women via GLP-1 [112]. These findings are in agreement with plants containing

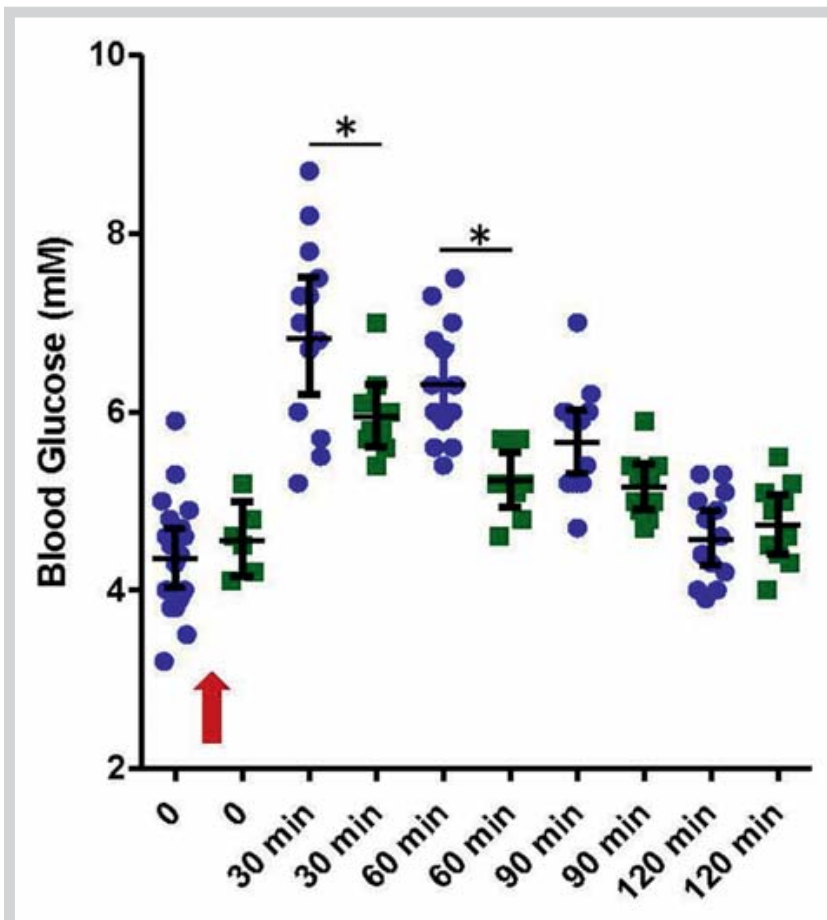

Fig. 2 Negative metabolic feedback by chlorophyllin (E141). Data show blood glucose levels after $75 \mathrm{~g}$ of glucose intake alone (blue) or in the presence of $1 \mathrm{~g}$ of chlorophyll (green) in healthy young men. Blood glucose was measured (capillary) prior to ingestion (time 0 ) and then every 30 min up to $120 \mathrm{~min}$. At $30 \mathrm{~min}$, the chlorophyllin group showed an average of $6.0 \pm 0.5 \mathrm{mM}$ blood glucose and the control group showed $6.9 \pm 1.0 \mathrm{mM}$. At $60 \mathrm{~min}$, the chlorophyllin group showed an average of $5.2 \pm 0.4 \mathrm{mM}$ blood glucose and the control group showed $6.3 \pm 0.6 \mathrm{mM}$. In both groups, at least nine individuals were measured. The arrow indicates glucose intake. The scatter blot shows mean values \pm SD. ${ }^{*} \mathrm{P}>0.05$. (Color figure available online only.)

general principles that lead to the secretion of GLP-1 [113,114]. This simple human study illustrates how widespread secondary metabolites such as chlorophyll may exert a negative metabolic feedback effect. Approximately 150 million people worldwide are affected by T2DM, and this figure is expected to double in the next 20 years. Diabetes leads to a reduced life expectancy and quality of life, as well as a greater risk of heart disease, stroke, peripheral neuropathy, renal disease, and blindness [115]. Highcarbohydrate diets, particularly in the form of high-glycemic index carbohydrates, have the ability to directly induce atherosclerosis [116]. Rather surprisingly, there are probably hundreds of reports in the scientific literature showing that phytochemicals affect insulin secretion and diabetes-related biomarkers in both animal models and humans (for selected reviews see [117121]). Authors usually emphasize particular groups of plants or natural products, primarily flavonoids. The metabolic plant feedback hypothesis, on the other hand, puts forward that the most common phytochemicals exert such effects and widespread dietary molecules like chlorophyll may play a role. Possibly, chronic intake of high amounts of chlorophyll may be more relevant than potentially potent minor phytochemicals in specific botanical drugs. 


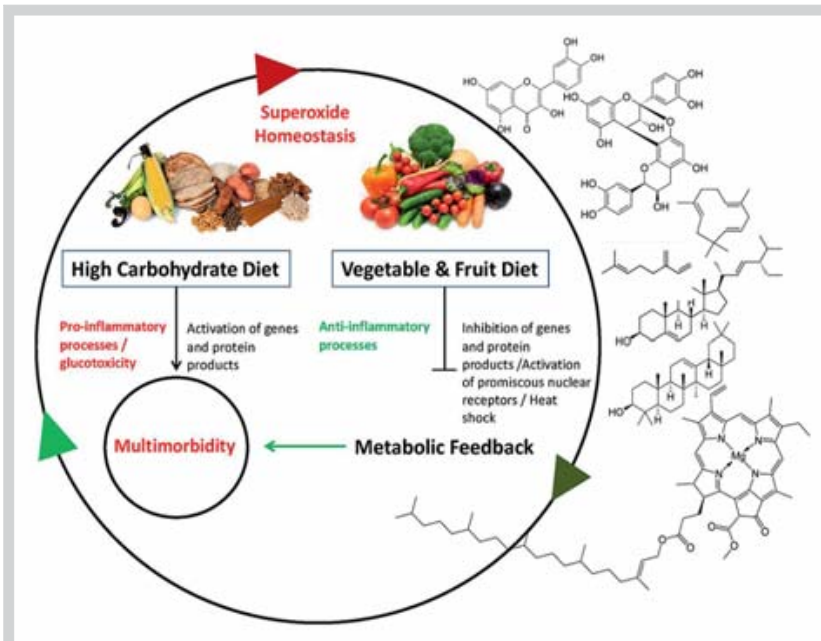

Fig. 3 Illustrative summary of the metabolic plant feedback hypothesis related to excess carbohydrate intake and nonspecific negative feedback of common dietary plant natural products. (Color figure available online only.)

\section{Adaptation to Chlorophyll - Does It Influence Our Health? $\nabla$}

Since the onset of the agricultural revolution, the consumption of green leafy vegetables does not fundamentally contribute to nutrient intake in humans anymore. Green vegetables may be indicators for general phytochemicals, just like big seeds and tubers stand for carbohydrates. Interestingly, all carbohydrate farming ethnic groups eat leafy vegetables. Leonti (2012) argued that leafy vegetables began to contribute substantially to the human diet only with the beginning of agriculture, when the ecological niche of weeds began to prosper [33]. I would like to take forward this assumption by stating that carbohydrate intake "coevolved" with the compensatory intake of phytochemicals. For example, apart from the ecological context [122], there is no good answer to the question why leafy vegetables like salads are cultivated worldwide. Rather than just stressing micronutrients (minerals, fibers, vitamins, etc.) one should also consider the potential role of general chlorophyll intake. Green vegetables contain a total chlorophyll content of about $10-30 \mathrm{mg} / \mathrm{g}$ dry weight, meaning that we may consume more than $1 \mathrm{~g}$ of chlorophyll daily, while some ingest nothing. Little is known about the degree of bioavailability and exact metabolism of chlorophylls A and B. Although bioavailabilty is probably poor, chlorophylls may still act locally in the gastrointestinal tract. Chlorophyllin, which is used in the food industry as coloring agent (E140), is used widely. The apparent lack of toxicity attributed to chlorophyllin led to the belief that it was poorly absorbed, but a study with humans shows that this is not true [123]. Results indicate that consumption of chlorophyll B-rich foods may diminish the adverse health effects induced by the chemotherapeutic agent cisplatin [124], suggesting inhibition of inflammation. Potential anti-inflammatory effects of chlorophylls have been described [125]. The Linus Pauling Institute Micronutrient Information Centre at Oregon State University comprehensively summarized the potential health effects of chlorophyll [126]. Moreover, the chlorophyll-derived metabolite phytanic acid $(\mathrm{PA})$ has been proposed to have utility for the treatment and prevention of T2DM [127], and to exert effects via peroxisome proliferator-activated receptors (PPARs) [128].
PA has also been shown to induce adipocyte differentiation [129, 130]. The origin of PA, which can also give rise to Refsum syndrome in which phytanoyl-CoA-hydroxylase is defective, is somewhat unclear [131]. PA is a chlorophyll metabolite of ruminants, and humans primarily ingest it via meat consumption [132]. Humans and rodents with impaired PA metabolism can accumulate toxic stores of PA that have deleterious effects on multiple organ systems. Recently, it was shown that, unlike humans, captive monkeys under a non-natural diet (high carbohydrate) could generate PA from chlorophyll [133]. In contrast to humans, monkeys derive significant amounts of phytanic acid from the hindgut fermentation of plant materials [134]. Thus, the evolutionary rates of genes and microbiota relevant to PA metabolism provide adaptive factors in a diet. Phytol, which is a hydrolysis product of chlorophylls and a poorly bioavailable dietary metabolic precursor of vitamins $\mathrm{K}$ and $\mathrm{E}$, exhibits numerous effects, including anti-inflammatory [135-137].

\section{Conclusions}

\section{$\nabla$}

In their seminal 1985 paper, Eaton and Konner [11] postulated that many of the chronic metabolic disorders now widespread in the industrialized world result from a way of life that is mismatched to human evolutionary history. The mismatch hypothesis has its origins in the "thrifty genotype" hypothesis [138] that populations who had remained hunter-gatherers into modern historical periods maintained traits that would favor insulin resistance and energy storage in times of famine. Those adaptations that appear to be strongly genetic likely reflect Neolithic, rather than Paleolithic, adaptations and are significantly influenced by human niche-constructing behavior [139]. Here, the likely impact of phytochemicals on this mismatch during early agriculture is discussed. In essence, high sugar intake is less toxic if accompanied by the intake of phytochemicals. The negative metabolic feedback of widespread phytochemicals in food, but also in herbal remedies, is mediated by weak network effects induced by chronic exposure. It is based on the assumption that numerous negligible inhibitory molecular effects can turn into a significant inhibition [51], and are opposed to the pharmacological paradigm of potent and selective "magic bullets". The consumption of excess carbohydrates without the intake of excess phytochemicals (which mediate the negative metabolic feedback) is postulated to be causative for morbidity ( $\bullet$ Fig. 3 ). A provocative assertion of the metabolic plant feedback hypothesis is that most of the orally administered medicinal plants (herbal medicines) are not more effective than the bulk of vegetable food, including spices. In fact, by consuming herbal medicines, similar biochemical mechanisms (often associated with metabolic and inflammatory processes) are inhibited, as with widespread dietary phytochemicals. It is not a new insight that we should eat more vegetables and fruits, but the correlation with carbohydrate intake has some interesting implications: The more frequently and the more diverse dietary phytochemicals are consumed, the more likely one gets a positive effect. Excluded from this are toxic plants, which have maybe only started to become used in the context of treating self-limited infectious diseases, or with the raise of herbal medicines. However, food staples and food-processing procedures introduced during the Neolithic and Industrial periods have fundamentally altered fundamental nutritional characteristics of ancestral hominin diets, including cooking food [140]. Never in the history of the human diet have we consumed more 
carbohydrates and less phytochemicals than today. A recent study has shown that a low-carbohydrate diet, but not a low-fat diet, improves health conditions in T2DM patients [141]. It would be interesting to see whether a high phytochemial diet could equally improve health conditions in T2DM patients. Maybe the high glucose intake worldwide could be compensated by an overall higher phytochemical intake? In summary, rather than looking for the needle in the haystack among phytochemicals, we should focus on the hay itself in diets. No disease that can be treated by diet should be treated with any other means.

\section{Supporting information}

Details on the homeostatic-type assessment that was carried out in order to assess the potentially negative impact of chlorophylltype molecules on blood glucose are available as Supporting Information.

\section{Acknowledgments}

$\nabla$

The EU MedPlant is a Marie Curie Initial Training Network (ITN) is acknowledged for financial support. The author acknowledges the reviewers for their critical and constructive comments.

\section{Conflict of Interest}

$\nabla$

The author has no conflict of interest.

\section{References}

1 Gertsch J. From ethnobotany to molecular pharmacognosy: a transdisciplinary approach. Ethnobotany of the Yanomamï-Amerindians in Venezuela, phytochemical and biological investigations on selected plants, development of a real-time PCR-based functional transcriptomics assay (FTA) [dissertation]. Zürich: ETH Zürich; 2002

2 Gertsch J, Stauffer W, Narváez A, Sticher O. Use and significance of palms (Arecaceae) among the Yanomamï in southern Venezuela. J Ethnobiol 2002; 22: 219-246

3 Headland TN. The wild yam question: How well could independent hunter-gatherers live in a tropical rain forest ecosystem? Hum Ecol 1987; 15: 463-491

4 Hardy K, Brand-Miller J, Brown KD, Thomas MG, Copeland L. The importance of dietary carbohydrate in human evolution. Q Rev Biol 2015; 90: 251-268

5 Perry GH, Dominy NJ, Claw KG, Lee AS, Fiegler H, Redon R, Werner J, Villanea FA, Mountain JL, Misra R, Carter NP, Lee C, Stone AC. Diet and the evolution of human amylase gene copy number variation. Nat Genet 2007; 39: 1256-1260

6 Blum K, Thanos PK, Gold MS. Dopamine and glucose, obesity, and reward deficiency syndrome. Front Psychol 2014; 5: 919

7 Voegtlin WL. The Stone Age Diet: based on in-depth Studies of human Ecology and the Diet of Man. New York: Vantage Press; 1975

8 Tapsell LC, Hemphill I, Cobiac L, Patch CS, Sullivan DR, Fenech M, Roodenrys S, Keogh JB, Clifton PM, Williams PG, Fazio VA, Inge KE. Health benefits of herbs and spices: the past, the present, the future. Med J Aust 2006; 185: S4-S24

9 Aggarwal BB, Van Kuiken ME, Iyer LH, Harikumar KB, Sung B. Molecular targets of nutraceuticals derived from dietary spices: potential role in suppression of inflammation and tumorigenesis. Exp Biol Med (Maywood) 2009; 234: 825-849

10 Diamond J. Evolution, consequences and future of plant and animal domestication. Nature 2002; 418: 700-707

11 Eaton SB, Konner M. Paleolithic nutrition. A consideration of its nature and current implications. N Engl J Med 1985; 312: 283-289

12 Lindeberg $S$. Food and Western Disease: Health and Nutrition from an evolutionary Perspective. Oxford (UK): Wiley-Blackwell; 2009

13 Fairweather-Tait SJ. Human nutrition and food research: opportunities and challenges in the post-genomic era. Philos Trans R Soc Lond B Biol Sci 2003; 358: 1709-1727
14 Hunter $P$. We are what we eat. The link between diet, evolution and non-genetic inheritance. EMBO Rep 2008; 9: 413-415

15 Lillycrop KA, Burdge GC. Maternal diet as a modifier of offspring epigenetics. J Dev Orig Health Dis 2015; 6: 88-95

16 Acton KJ, Burrows NR, Moore K, Querec L, Geiss LS, Engelgau MM. Trends in diabetes prevalence among American Indian and Alaska native children, adolescents, and young adults. Am J Public Health 2002; 92: 1485-1490

17 Wendorf $M$. Diabetes, the ice free corridor, and the Paleoindian settlement of North America. Am J Phys Anthropol 1989; 79: 503-520

18 Lindgärde F, Ercilla MB, Correa LR, Ahrén B. Body adiposity, insulin, and leptin in subgroups of Peruvian Amerindians. High Alt Med Biol 2004; 5: 27-31

19 Hanley AJ, Harris SB, Gittelsohn J, Wolever TM, Saksvig B, Zinman B. Overweight among children and adolescents in a Native Canadian community: prevalence and associated factors. Am J Clin Nutr 2000; 71: 693-700

20 Bradshaw BS, Blanchard S, Thompson GH. Emergence of diabetes mellitus in a Mexican-origin population: a multiple cause-of-death analysis. Soc Biol 1995; 42: 36-49

21 Gracey M. New World syndrome in Western Australian aborigines. Clin Exp Pharmacol Physiol 1995; 22: 220-225

22 London DS, Beezhold B. A phytochemical-rich diet may explain the absence of age-related decline in visual acuity of Amazonian huntergatherers in Ecuador. Nutr Res 2015; 35: 107-117

23 Evans-Pritchard EE. Witchcraft, Oracles and Magic among the Azande. Oxford, UK: Clarendon Press; 1937

24 Eliade $M$. Le Chamanisme et les Techniques archaïques de l'Extase. Paris: Payot; 1951

25 Voeks RA, Sercombe P. The scope of hunter-gatherer ethnomedicine. Soc Sci Med 2000; 51: 679-690

26 Zerries O, Schuster M. Mahekodotedi: Monographie eines Dorfes der Waika-Indianer (Yanoama) am oberen Orinoco (Venezuela). München: K. Renner Verlag; 1974

27 Milliken $W$, Albert $B$. The use of medicinal plants by the Yanomam Indians of Brazil. Econ Bot 1996; 50: 10-25

28 Alexiadis MN. Ethnobotany of the Ese Eja: plants, health, and change in an Amazonian society [dissertation]. City University of New York; 1999

29 Kahlheber S, Neumann K. The development of plant cultivation in semiarid West Africa. In: Denham T, Iriarte J, Vrydaghs L, editors. Rethinking agriculture: archaeological and ethnoarchaeological perspectives (One World Archaeology 51). Walnut Creek, CA: Left Coast Press; 2007: 320-346

30 Cordain L, Eaton SB, Miller JB, Mann N, Hill K. The paradoxical nature of hunter-gatherer diets: meat-based, yet non-atherogenic. Eur J Clin Nutr 2002; 56: 42-52

31 Etkin NL, Ross PJ. Food as medicine and medicine as food: an adaptive framework for the interpretation of plant utilization among the Hausa of northern Nigeria. Soc Sci Med 1982; 16: 1559-1573

32 Johns T. With bitter Herbs they shall eat it: chemical Ecology and the Origins of human Diet and Medicine (Arizona Studies in Human Ecology). Tucson, AZ: University of Arizona Press; 1990

33 Leonti $M$. The co-evolutionary perspective of the food-medicine continuum and wild gathered and cultivated vegetables. Genet Resour Crop Evol 2012; 59: 1295-1302

34 Hou Y, Jiang JG. Origin and concept of medicine food homology and its application in modern functional foods. Food Funct 2013; 4: 17271741

35 Bisson J, McAlpine JB, Friesen JB, Chen SN, Graham J, Pauli GF. Can invalid bioactives undermine natural product-based drug discovery? J Med Chem 2016; 59: 1671-1690

36 Baell JB. Feeling nature's PAINS: natural products, natural product drugs, and pan assay interference compounds (PAINS). J Nat Prod, advance online publication 22 February 2016; DOI: 10.1021/acs. jnatprod.5b00947

37 Ingólfsson HI, Thakur P, Herold KF, Hobart EA, Ramsey NB, Periole X, de Jong DH, Zwama M, Yilmaz D, Hall K, Maretzky T, Hemmings Jr. HC, Blobel C, Marrink SJ, Koçer A, Sack JT, Andersen OS. Phytochemicals perturb membranes and promiscuously alter protein function. ACS Chem Biol 2014; 9: 1788-1798

38 Wang L, Waltenberger B, Pferschy-Wenzig EM, Blunder M, Liu X, Malainer C, Blazevic T, Schwaiger S, Rollinger JM, Heiss EH, Schuster D, Kopp B, Bauer R, Stuppner H, Dirsch VM, Atanasov AG. Natural product agonists of peroxisome proliferator-activated receptor gamma (PPARY): a review. Biochem Pharmacol 2014; 92: 73-89 
39 Li L, Bonneton F, Chen XY, Laudet V. Botanical compounds and their regulation of nuclear receptor action: the case of traditional Chinese medicine. Mol Cell Endocrinol 2015; 401: 221-237

40 Mandlekar S, Hong JL, Kong AN. Modulation of metabolic enzymes by dietary phytochemicals: a review of mechanisms underlying beneficial versus unfavorable effects. Curr Drug Metab 2006; 7: 661-675

41 Ohnishi K, Ohkura S, Nakahata E, Ishisaka A, Kawai Y, Terao J, Mori T, Ishii T, Nakayama T, Kioka N, Matsumoto S, Ikeda Y, Akiyama M, Irie K, Murakami A. Non-specific protein modifications by a phytochemical induce heat shock response for self-defense. PLoS One 2013; 8: e58641

42 Virgili F, Marino M. Regulation of cellular signals from nutritional molecules: a specific role for phytochemicals, beyond antioxidant activity. Free Radic Biol Med 2008; 45: 1205-1216

43 Remely M, Lovrecic L, de la Garza AL, Migliore L, Peterlin B, Milagro FI, Martinez AJ, Haslberger AG. Therapeutic perspectives of epigenetically active nutrients. Br J Pharmacol 2015; 172: 2756-2768

44 Joven J, Micol V, Segura-Carretero A, Alonso-Villaverde C, Menéndez JA. Bioactive Food Components Platform. Polyphenols and the modulation of gene expression pathways: can we eat our way out of the danger of chronic disease? Crit Rev Food Sci Nutr 2014; 54: 985-1001

45 Szarc vel Szic K, Declerck K, Vidaković M, Vanden Berghe W. From inflammaging to healthy aging by dietary lifestyle choices: is epigenetics the key to personalized nutrition? Clin Epigenetics 2015; 7: 33

46 Gertsch J, Viveros-Paredes JM, Taylor P. Plant immunostimulants-scientific paradigm or myth? J Ethnopharmacol 2011; 136: 385-391

47 Nathan R, Schurr FM, Spiegel O, Steinitz O, Trakhtenbrot A, Tsoar A. Mechanisms of long-distance seed dispersal. Trends Ecol Evol 2008; 23: 638-647

48 Fuller DQ. Contrasting patterns in crop domestication and domestication rates: recent archaeobotanical insights from the old World. Ann Bot 2007; 100: 903-924

49 Linus Pauling Institute, Micronutrient Information Center. Phytochemicals. Available at http://lpi.oregonstate.edu/mic/dietary-factors/ phytochemicals. Accessed March 10, 2016

50 Gertsch J. How scientific is the science in ethnopharmacology? Historical perspectives and epistemological problems. J Ethnopharmacol 2009; 122: 177-183

51 Gertsch J. Botanical drugs, synergy, and network pharmacology: forth and back to intelligent mixtures. Planta Med 2011; 77: 1086-1098

52 Butterweck $V$, Nahrstedt $A$. What is the best strategy for preclinical testing of botanicals? A critical perspective. Planta Med 2012; 78: 747-754

53 Terahara N. Flavonoids in foods: a review. Nat Prod Commun 2015; 10 : 521-528

54 Tholl $D$. Biosynthesis and biological functions of terpenoids in plants. Adv Biochem Eng Biotechnol 2015; 148: 63-106

55 Liu RH. Health-promoting components of fruits and vegetables in the diet. Adv Nutr 2013; 4: 384S-392S

56 Gerber LM, Williams GC, Gray SJ. The nutrient-toxin dosage continuum in human evolution and modern health. Q Rev Biol 1999; 74: 273-289

57 Parsons PA. The metabolic cost of multiple environmental stresses: Implications for climatic change and conservation. Trends Ecol Evol 1990; 5: 315-317

58 Heinrich M, Prieto JM. Diet and healthy ageing 2100: will we globalise local knowledge systems? Ageing Res Rev 2008; 7: 249-274

59 Gostner JM, Becker K, Ueberall F, Fuchs D. The good and bad of antioxidant foods: An immunological perspective. Food Chem Toxicol 2015; 80: $72-79$

60 De Roos B, Duthie GG. Role of dietary pro-oxidants in the maintenance of health and resilience to oxidative stress. Mol Nutr Food Res 2015; 59: 1229-1248

61 Benzie IF. Evolution of dietary antioxidants. Comp Biochem Physiol A Mol Integr Physiol 2003; 136: 113-126

62 González-Castejón M, Rodriguez-Casado A. Dietary phytochemicals and their potential effects on obesity: a review. Pharmacol Res 2011; 64: 438-455

63 Cicero AF, Colletti A. Role of phytochemicals in the management of metabolic syndrome. Phytomedicine, advance online publication 11 December 2015; DOI: 10.1016/j.phymed.2015.11.009

64 Li YH, Niu YB, Sun Y, Zhang F, Liu CX, Fan L, Mei QB. Role of phytochemicals in colorectal cancer prevention. World J Gastroenterol 2015; 21: 9262-9272

65 Alasalvar C, Bolling BW. Review of nut phytochemicals, fat-soluble bioactives, antioxidant components and health effects. Br J Nutr 2015; 113: S68-S78
66 Slavin JL, Lloyd B. Health benefits of fruits and vegetables. Adv Nutr 2012; 3: 506-516

67 Gordon $M H$. Significance of dietary antioxidants for health. Int J Mol Sci 2012; 13: 173-179

68 Galal AM, Walker LA, Khan IA. Induction of GST and related events by dietary phytochemicals: sources, chemistry, and possible contribution to chemoprevention. Curr Top Med Chem 2015; 14: 2802-2821

69 Shankar S, Kumar D, Srivastava RK. Epigenetic modifications by dietary phytochemicals: implications for personalized nutrition. Pharmacol Ther 2013; 138: 1-17

70 Johnson IT, Belshaw NJ. The effect of diet on the intestinal epigenome. Epigenomics 2014; 6: 239-251

71 Li CC, Cropley JE, Cowley MJ, Preiss T, Martin DI, Suter CM. A sustained dietary change increases epigenetic variation in isogenic mice. PLoS Genet 2011; 7: e1001380

72 Thorburn AN, Macia L, Mackay CR. Diet, metabolites, and "western-lifestyle" inflammatory diseases. Immunity 2014; 40: 833-842

73 Riccardi G, Rivellese AA. Dietary treatment of the metabolic syndromethe optimal diet. Br J Nutr 2000; 83: S143-S148

74 Stanhope $K L$. Sugar consumption, metabolic disease and obesity: The state of the controversy. Crit Rev Clin Lab Sci 2016; 53: 52-67

75 Cabrera Escobar MA, Veerman JL, Tollman SM, Bertram MY, Hofman KJ. Evidence that a tax on sugar sweetened beverages reduces the obesity rate: a meta-analysis. BMC Public Health 2013; 13: 1072

76 Ruel G, Shi Z, Zhen S, Zuo H, Kröger E, Sirois C, Lévesque JF, Taylor AW. Association between nutrition and the evolution of multimorbidity: the importance of fruits and vegetables and whole grain products. Clin Nutr 2014; 33: 513-520

77 Alonso-Castro AJ, Domínguez F, Zapata-Morales JR, Carranza-Álvarez C. Plants used in the traditional medicine of Mesoamerica (Mexico and Central America) and the Caribbean for the treatment of obesity. J Ethnopharmacol 2015; 175: 335-345

78 Etkin NL. Multidisciplinary perspectives in the interpretation of plants used in indigenous medicine and diet. In: Etkin NL, editor. Plants in indigenous medicine and diet: biobehavioral approaches. Bedford Hills, NY: Redgrave Press; 1986: 1-29

79 Salas-Salvadó J, Guasch-Ferré M, Bulló M, Sabaté J. Nuts in the prevention and treatment of metabolic syndrome. Am J Clin Nutr 2014; 100 399S-407S

80 Heber D. Herbal preparations for obesity: are they useful? Prim Care 2003; 30: 441-463

81 Cercato LM, White PA, Nampo FK, Santos MR, Camargo EA. A systematic review of medicinal plants used for weight loss in Brazil: Is there potential for obesity treatment? J Ethnopharmacol 2015; 176: 286-296

82 Ezuruike UF, Prieto JM. The use of plants in the traditional management of diabetes in Nigeria: pharmacological and toxicological considerations. J Ethnopharmacol 2014; 155: 857-924

83 J Afolayan A, O Sunmonu T. In vivo studies on antidiabetic plants used in South African herbal medicine. J Clin Biochem Nutr 2010; 47: 98-106

84 Jouad H, Haloui M, Rhiouani H, El Hilaly J, Eddouks M. Ethnobotanical survey of medicinal plants used for the treatment of diabetes, cardiac and renal diseases in the North centre region of Morocco (FezBoulemane). J Ethnopharmacol 2001; 77: 175-182

85 Ríos JL, Francini F, Schinella GR. Natural products for the treatment of type 2 diabetes mellitus. Planta Med 2015; 81: 975-994

86 Parikh NH, Parikh PK, Kothari C. Indigenous plant medicines for health care: treatment of diabetes mellitus and hyperlipidemia. Chin J Nat Med 2014; 12: 335-344

87 Rastogi S, Pandey MM, Rawat AK. Traditional herbs: a remedy for cardiovascular disorders. Phytomedicine, advance online publication 10 November 2015; DOI: 10.1016/j.phymed.2015.10.012

88 Efferth T, Kaina $B$. Toxicities by herbal medicines with emphasis to traditional Chinese medicine. Curr Drug Metab 2011; 12: 989-996

89 Dutra RC, Campos MM, Santos AR, Calixto JB. Medicinal plants in Brazil: Pharmacological studies, drug discovery, challenges and perspectives. Pharmacol Res, advance online publication 23 January 2016; DOI: 10.1016/j.phrs.2016.01.021

90 Hadjzadeh MA, Rajaei Z, Moradi R, Ghorbani A. Effects of hydroalcoholic extract of watercress (Nasturtium officinale) leaves on serum glucose and lipid levels in diabetic rats. Indian J Physiol Pharmacol 2015; 59: 223-230

91 Dudzińska $D$, Boncler $M$, Watala $C$. The cardioprotective power of leaves. Arch Med Sci 2015; 11: 819-839 
92 Zhou Z, Li D, Zhou H, Lin X, Li C, Tang M, Feng Z, Li M. Plants and their bioactive compounds with the potential to enhance mechanisms of inherited cardiac regeneration. Planta Med 2015; 81: 637-647

93 Chen S, Zhu Y, Liu Z, Gao Z, Li B, Zhang D, Zhang Z, Jiang X, Liu Z, Meng L, Yang Y, Shi B. Grape seed proanthocyanidin extract ameliorates diabetic bladder dysfunction via the activation of the Nrf2 pathway. PLoS One 2015; 10: e0126457

94 Vujicic M, Nikolic I, Kontogianni VG, Saksida T, Charisiadis P, OrescaninDusic Z, Blagojevic D, Stosic-Grujicic S, Tzakos AG, Stojanovic I. Methanolic extract of Origanum vulgare ameliorates type 1 diabetes through antioxidant, anti-inflammatory and anti-apoptotic activity. Br J Nutr 2015; 113: 770-782

95 Leiherer A, Mündlein A, Drexel $H$. Phytochemicals and their impact on adipose tissue inflammation and diabetes. Vascul Pharmacol 2013; 58: $3-20$

96 Grant SJ, Bensoussan A, Chang D, Kiat H, Klupp NL, Liu JP, Li X. Chinese herbal medicines for people with impaired glucose tolerance or impaired fasting blood glucose. Cochrane Database Syst Rev 2009; 4 : CD006690

97 Lind J. A Treatise of Scurvy in three Parts. Edinburgh: Kincaid \& Donaldson; 1753

98 Spedding $S$. Vitamins are more Funky than Casimir thought. Australas Med J 2013; 6: 104-106

99 Semba RD. The discovery of the vitamins. Int J Vitam Nutr Res 2012; 82: $310-315$

100 Carpenter, KJ. The Nobel Prize and the discovery of vitamins. Available at http://www.nobelprize.org/nobel_prizes/themes/ medicine/carpenter/. Accessed March 10, 2016

101 Gertsch J, Leonti M, Raduner S, Racz I, Chen JZ, Xie XQ Altmann KH, Karsak M, Zimmer A. Beta-caryophyllene is a dietary cannabinoid. Proc Natl Acad Sci U S A 2008; 105: 9099-9104

102 Gertsch J. Anti-inflammatory cannabinoids in diet: Towards a better understanding of $\mathrm{CB}(2)$ receptor action? Commun Integr Biol 2008; 1: $26-28$

103 Sharma C, Al Kaabi J, Nurulain SM, Goyal SN, Kamal MA, Ojha S. Polypharmacological properties and therapeutic potential of $\beta$-caryophyllene: a dietary phytocannabinoid of pharmaceutical promise. Curr Pharm Des [in press]

104 Jacobs DR Jr, Steffen LM. Nutrients, foods, and dietary patterns as exposures in research: a framework for food synergy. Am J Clin Nutr 2003; 78: 508S-513S

105 Ulrich-Merzenich G, Zeitler H, Vetter H, Kraft K. Synergy research: vitamins and secondary plant components in the maintenance of the redox-homeostasis and in cell signaling. Phytomedicine 2009; 16: 2-16

106 Zhang A, Sun H, Wang X. Potentiating therapeutic effects by enhancing synergism based on active constituents from traditional medicine. Phytother Res 2014; 28: 526-533

107 Matthews DR, Hosker JP, Rudenski AS, Naylor BA, Treacher DF, Turner $R C$. Homeostasis model assessment: insulin resistance and beta-cell function from fasting plasma glucose and insulin concentrations in man. Diabetologia 1985; 28: 412-419

108 Jenkins DJ, Kendall CW, Augustin LS, Franceschi S, Hamidi M, Marchie A, Jenkins $A L$, Axelsen M. Glycemic index: overview of implications in health and disease. Am J Clin Nutr 2002; 76: 266S-273S

109 Zeevi D, Korem T, Zmora N, Israeli D, Rothschild D, Weinberger A, BenYacov O, Lador D, Avnit-Sagi T, Lotan-Pompan M, Suez J, Mahdi JA, Matot E, Malka G, Kosower N, Rein M, Zilberman-Schapira G, Dohnalová L, Pevsner-Fischer M, Bikovsky R, Halpern Z, Elinav E, Segal $E$. Personalized nutrition by prediction of glycemic responses. Cell 2015; 163: 1079-1094

110 Montelius C, Gustafsson K, Weström B, Albertsson PÅ, Emek SC, Rayner $M$, Erlanson-Albertsson $C$. Chloroplast thylakoids reduce glucose uptake and decrease intestinal macromolecular permeability. Br J Nutr 2011; 106: 836-844

111 Montelius C, Szwiec K, Kardas M, Lozinska L, Erlanson-Albertsson C, Pierzynowski S, Rehfeld JF, Weström B. Dietary thylakoids suppress blood glucose and modulate appetite-regulating hormones in pigs exposed to oral glucose tolerance test. Clin Nutr 2014; 33: 1122-1126

112 Montelius C, Erlandsson D, Vitija E, Stenblom EL, Egecioglu E, ErlansonAlbertsson C. Body weight loss, reduced urge for palatable food and increased release of GLP-1 through daily supplementation with greenplant membranes for three months in overweight women. Appetite 2014; 81: 295-304

113 Bligh HF, Godsland IF, Frost G, Hunter KJ, Murray P, MacAulay K, Hyliands D, Talbot DC, Casey J, Mulder TP, Berry MJ. Plant-rich mixed meals based on Palaeolithic diet principles have a dramatic impact on incretin, peptide YY and satiety response, but show little effect on glucose and insulin homeostasis: an acute-effects randomised study. Br J Nutr 2015; 113: 574-584

114 Kim KS, Jang HJ. Medicinal plants qua glucagon-like peptide-1 secretagogue via intestinal nutrient sensors. Evid Based Complement Alternat Med 2015; 2015: 171742

115 Freeman $H$, Cox $R D$. Type-2 diabetes: a cocktail of genetic discovery. Hum Mol Genet 2006; 15: R202-R209

116 Kopp $W$. The atherogenic potential of dietary carbohydrate. Prev Med 2006; 42: 336-342

117 Vinayagam $R$, Jayachandran $M, X u$ B. Antidiabetic effects of simple phenolic acids: a comprehensive review. Phytother Res 2016; 30: 184-199

118 Elekofehinti 00. Saponins: Anti-diabetic principles from medicinal plants - A review. Pathophysiology 2015; 22: 95-103

119 Guo H, Ling W. The update of anthocyanins on obesity and type 2 diabetes: experimental evidence and clinical perspectives. Rev Endocr Metab Disord 2015; 16: 1-13

120 Pathak M. Diabetes mellitus type 2 and functional foods of plant origin. Recent Pat Biotechnol 2014; 8: 160-164

121 Singhal P, Kaushik G, Mathur P. Antidiabetic potential of commonly consumed legumes: a review. Crit Rev Food Sci Nutr 2014; 54: 655672

122 Heinrich M, Nebel S, Leonti M, Rivera D, Obón C. 'Local Food-Nutraceuticals': bridging the gap between local knowledge and global needs. Forum Nutr. 2006; 59: 1-17

123 Egner PA, Stansbury KH, Snyder EP, Rogers ME, Hintz PA, Kensler TW. Identification and characterization of chlorin e(4) ethyl ester in sera of individuals participating in the chlorophyllin chemoprevention trial. Chem Res Toxicol 2000; 13: 900-906

124 Serpeloni JM, Batista BL, Angeli JP, Barcelos GR, Bianchi Mde L, Barbosa Jr. F, Antunes LM. Antigenotoxic properties of chlorophyll b against cisplatin-induced DNA damage and its relationship with distribution of platinum and magnesium in vivo. J Toxicol Environ Health A 2013; 76 : 345-353

125 Subramoniam A, Asha VV, Nair SA, Sasidharan SP, Sureshkumar PK, Rajendran KN, Karunagaran D, Ramalingam K. Chlorophyll revisited: anti-inflammatory activities of chlorophyll a and inhibition of expression of TNF- $\alpha$ gene by the same. Inflammation 2012; 35: 959-966

126 Higdon J. Chlorophyll and Chlorophyllin. Available at http://lpi. oregonstate.edu/book/export/html/456. Accessed March 7, 2016

127 McCarty MF. The chlorophyll metabolite phytanic acid is a natural rexinoid - potential for treatment and prevention of diabetes. Med Hypotheses 2001; 56: 217-219

128 Heim M, Johnson J, Boess F, Bendik I, Weber P, Hunziker W, Fluhmann B. Phytanic acid, a natural peroxisome proliferator-activated receptor (PPAR) agonist, regulates glucose metabolism in rat primary hepatocytes. FASEB J 2002; 16: 718-720

129 Schlüter A, Barberá MJ, Iglesias R, Giralt M, Villarroya F. Phytanic acid, a novel activator of uncoupling protein-1 gene transcription and brown adipocyte differentiation. Biochem J 2002; 362: 61-69

130 Schlüter A, Giralt M, Iglesias R, Villarroya F. Phytanic acid, but not pristanic acid, mediates the positive effects of phytol derivatives on brown adipocyte differentiation. FEBS Lett 2002; 517: 83-86

131 Baxter JH. Absorption of chlorophyll phytol in normal man and in patients with Refsum's disease. J Lipid Res 1968; 9: 636-641

132 Hellgren LI. Phytanic acid - an overlooked bioactive fatty acid in dairy fat? Ann N Y Acad Sci 2010; 1190: 42-49

133 Moser AB, Hey J, Dranchak PK, Karaman MW, Zhao J, Cox LA, Ryder OA Hacia JG. Diverse captive non-human primates with phytanic aciddeficient diets rich in plant products have substantial phytanic acid levels in their red blood cells. Lipids Health Dis 2013; 12: 10

134 Watkins PA, Moser AB, Toomer CB, Steinberg SJ, Moser HW, Karaman MW, Ramaswamy K, Siegmund KD, Lee DR, Ely JJ, Ryder OA, Hacia JG. Identification of differences in human and great ape phytanic acid metabolism that could influence gene expression profiles and physiological functions. BMC Physiol 2010; 10: 19

135 Baxter JH, Steinberg $D$. Absorption of phytol from dietary chlorophyll in the rat. J Lipid Res 1967; 8: 615-620

136 Silva RO, Sousa FB, Damasceno SR, Carvalho NS, Silva VG, Oliveira FR, Sousa DP, Aragão KS, Barbosa AL, Freitas RM, Medeiros JV. Phytol, a diterpene alcohol, inhibits the inflammatory response by reducing cytokine production and oxidative stress. Fundam Clin Pharmacol 2014; 28: 455-464 
137 De Moraes J, de Oliveira RN, Costa JP, Junior AL, de Sousa DP, Freitas RM, Allegretti SM, Pinto PL. Phytol, a diterpene alcohol from chlorophyll, as a drug against neglected tropical disease Schistosomiasis mansoni. PLoS Negl Trop Dis 2014; 8: e2617

138 Neel JV. Diabetes mellitus: a "thrifty" genotype rendered detrimental by "progress"? Am J Hum Genet 1962; 14: 353-362

139 Turner BL, Thompson AL. Beyond the Paleolithic prescription: incorporating diversity and flexibility in the study of human diet evolution. Nutr Rev 2013; 71: 501-510
140 Cordain L, Eaton SB, Sebastian A, Mann N, Lindeberg S, Watkins BA, O'Keefe JH, Brand-Miller J. Origins and evolution of the Western diet: health implications for the 21st century. Am J Clin Nutr 2005; 81: 341-354

141 Guldbrand H, Lindström T, Dizdar B, Bunjaku B, Östgren CJ, Nystrom FH, Bachrach-Lindström M. Randomization to a low-carbohydrate diet advice improves health related quality of life compared with a low-fat diet at similar weight-loss in Type 2 diabetes mellitus. Diabetes Res Clin Pract 2014; 106: 221-227 